\title{
Value in Megaprojects
}

\author{
Gloria O Oliomogbe \\ Civil Engineering, University of Leeds, \\ Leeds, United Kingdom \\ cngoo@leeds.ac.uk
}

\author{
Nigel J Smith \\ Head of School, Civil engineering, \\ University of Leeds, Leeds, United Kingdom \\ n.j.smith@leeds.ac.uk
}

DOI 10.5592/otmcj.2012.3.5 Research Paper

Project management Value has moved from ideas of 'Value management' TO IDEAS OF 'UNDERSTANDING HOW STAKEHOLDERS VALUE DIFFERENT THINGS'. In line with this new paradigm, value in megaprojects is influenced by the complex morass of stakeholders involved. This paper explores how stakeholders engage with the megaproject delivery process and value creation. From extant literature, the author reviews the definition of megaprojects and discusses their characteristics. Value and stakeholder value was also discussed. It was proposed that internal stakeholders are concerned with the value from 'project management deployment' while external stakeholders are primarily concerned with the 'value from project outcome'. Using a framework, the relationship between external stakeholders and value from project outcome was argued for. Internal stakeholders and the relationship with value from project management deployment were also argued for. Hence, a Value framework that can be used to determine what value needs to be generated for internal and external stakeholders is proposed. Future research is discussed including the need to further develop this value framework to identify different internal and external stakeholder value across project life cycle and product life cycle.

\section{Introduction}

The discussion of value has become increasingly important especially as the question 'value for whom' (Winter et al., 2006) resonates in project delivery. But project management value has moved from ideas of 'value management' to ideas of 'understanding how stakeholders value different things'. This is shown by how the meaning of the term 'value' in the project management literature has over time changed from the perspective of value as 'Earned value management' (i.e. cost related) to value as 'contributing to competitive advantage and sustainability' (the way permanent organisations now view it.) A search of the word 'value' in the proj- ect management literature (The International Journal of Project Management (IJPM) and Project Management Journal (PMJ)) will result in several articles on Earned Value Management (EVM); and most of the articles that are not EVM related that have value in their titles are from more recent years. Some researchers have argued that the reason for this is that the business environment is dynamic characterised by globalisation and overcompetition (Foricel and Miller, 2001) with increasing competition and innovation (Hobbs et al., 2008). While others have argued that in recent years, how organisations compete and create value has changed (Welzl, 2011., Jia et al., 2011). 
In line with the ideas of 'understanding how stakeholders value different things', value in megaproject is influenced by the complex morass of stakeholders involved. But from existing literature, many authors have only focused on a limited definition of value from project management (Thomas and Mullaly, 2009). Thomas and Mullaly imply that value is benefits (financial, none financial, tangible and intangible) associated with an investment. This implied definition of value is also echoed in (Patah and de Carvalho, 2007) as 'a result after an investment' and in (Hurt and Thomas, 2009) '....gain value from investment in project management...'. Therefore for the purpose of this paper, value is defined as the benefits generated for project stakeholders as a result of project management deployment. Thomas and Mullally also suggest that the value that is generated by the implementation of project management is influenced by the business orientation of the organisation and the environment in which it operates in. Similarly, value in megaprojects would be influenced by the organisation (e.g. special purpose motor) and the environment (e.g. multiple stakeholders with complex relationships). Using the submission by Winter and colleagues (Winter et al., 2006) that there is the need for multiple images in the management of project; the author by using the lens of value creation for stakeholders sheds more light on megaproject value. The approach is to understand how multiple stakeholders in the megaproject complex environment engage with the megaproject delivery process and value creation. To do this, the paper begins with the review of literature on megaproject definitions and discusses their characteristics. This is followed by defining value and discussing stakeholder value. Using a framework, external stakeholders and value from the project outcome are discussed. Internal stakeholders and value from project management deployment are then discussed. Lastly, the Value framework is discussed and how it might be used in the future.

\section{Megaproject Definition}

Different terms are used to describe large projects in literature such as complex projects, major projects, giant projects and megaprojects (Ruuska et al., 2009). The author, by searching for the terms 'large projects', 'major projects', 'mega projects' and 'megaprojects' in IJPM and PMJ, observed a trend where several articles were written about large projects in the 1980 s and then there was a lull in the 1990 s but since 2000 , several more articles have been written with the term 'megaproject' featuring more in titles of more recent journal papers.

Several authors have defined megaprojects and discussed its characteristics and Table 1 is a compilation of some megaproject definitions by different researchers from the review of literature

As shown in Table 1, the various researchers' definition of megaproject has common characteristics which are highlighted below:

$\checkmark$ Time: More than a decade (often more than one political dispensation)

- Cost: Greater than $\mathrm{f} 100$ million

- Colossal use of resources (money, human, equipment etc)

Owner: Government/Public sector

$>$ Large Size

Risk and uncertainty

> Technological innovation / insufficient experience

- Social, political, economic and environmental impacts

Multiple owners

> Complexity

> Poor performance (cost, quality, performance etc)

- Control issues/changing priorities

- Indirect benefits to non users of the project

Located in inhospitable places

> Career risk

\section{Discussion: The Literature on Megaproject Definition}

The most striking disparity about the definitions of megaprojects has to do with costs; different authors have different cost values. For example, the Megaproject COST action defines megaprojects as extremely large-scale investment projects that typically cost more than EUR 0.5 billion (Megaproject Cost Action, 2012) while Sturup uses the $f_{150}$ million bench mark (Sturup, 2009). The literature review suggests that projects with cost above a value of $f 100$ million exhibiting at least all the common characteristics highlighted can be considered to be a megaproject.

Furthermore, by inspection of the definitions of megaprojects based on the year the articles were written, there is now more focus on the structure of the megaproject organisation (stakeholders, their roles and control). For example, the more recent definitions by (Sanderson, 2012) highlight the client/owner and contractor roles and the Megaproject Cost Action definition also brings to focus the relationship between client/owners and contractors. This is due to the increasing importance of the relationship between project owners and contractors as a result of the need for transparency and accountability and evolving definition of megaproject stakeholder value.

Another important and common point raised is that megaprojects often perform poorly in terms of the cost, quality, duration and performance and these have a direct impact on stakeholder value (Megaproject Cost Action, 2012). Persistent cost over runs and over estimation of economic benefits suggests that the wrong projects are selected, often not viable and costing more than they should (Flyvbjerg et al., 2003, Sturup, 2009). Extant literature show that the track records of large projects are fundamentally poor (Ruuska et al., 2009) even though they have become more popular (Sanderson, 2012) with project outcomes which sometimes are not in the best interest of the public (van Marrewijk et al., 2008). Megaprojects underperformance also affects social acceptability, regulatory 
- High investment expenditures of US\$1 billion or more

(Bruzelius et al., 2002)

- Long lifetime of 50 years and more

- Considerable uncertainty with respect to the demand forecasts and cost estimates

- Considerable share of indirect benefits which cannot be captured by the operator (benefits not occurring to the users of the project rather than to third parties)

- The project delivers a substantial piece of physical infrastructure/capital asset with a life expectancy measured in decades

- The client is often a government or public sector organisation

- The main contractor or consortium of contractors are usually privately owned and financed

- The contractors often retains ownership stake in the infrastructure/asset after the construction phase is completed-typically a minority shareholder in a special purpose vehicle (SPV) and is paid by the client for the service that flows from the asset's operation or use over a number of years.

(Sanderson, 2012)

Frick calls the six C's:

(Sturup, 2009)

- Colossal in size and scope

- Captivating because of their size, engineering achievements or aesthetic design

- Costly- often undercosted

- Controversial

- Complex

- Have control issues

Multiple organisations seeking success with different objectives

(Ruuska et al., 2009)

Changing priorities by project objectives

The project being subject to the impact of a wider socio-political environment

- Value of over f15omillion

- Complex management structure

(Stoddart-Stones, 1988)

- Politics playing an important role in how senior management appointments and activities are defined.

Sykes outlines nine characteristics:

(Haynes, 2002)

- Size and the likelihood of multiple owners

- Public opposition to the likely social, economic, political and environmental impacts

- Time-a decade or more to plan, design, finance and build

- Located in remote and or inhospitable areas

- Potential to destabilise markets because of the demand on labour and suppliers

- Unique risk, especially when projects spans economic cycles

- Financing difficulties

- Insufficient experience, especially in managing complex undertakings

- Career risks, because most of the undertaking do not advance past the planning stage and therefore, pose an unpopular career course for senior management (Keegan, 2004)

Table 1 Summary of Characteristics of Several Authors Source: Author

compatibility and future business opportunities (Eweje et al., 2012). Different reasons have been given for the poor performance of megaprojects. For example, Aaltonen (2011) states that external and internal pressures for projects to be more environmentally and socially responsible have been on the rise. A point also argued vigorously in their book (Flyvbjerg et al., 2003). Megaprojects costs are intentionally underestimated and benefits overestimated because of vested interests hence the poor performance of project implemented (Flyvbjerg et al., 2003). In their review of literature on reasons for poor performance, they concluded that there were three major arguments: type A, B and C (Sanderson, 2012). Type $A$ arguments are based on the opinion that megaprojects often underperform because non-viable projects are so reg- ularly undertaken while for Type $B$, the main argument is that the poor performance is best explained by the fact that organisations are unable to deal with the risks and complexities associated with megaprojects. For Type C, the argument is that megaprojects are typically characterised by multiple and diverse discusses, cultures and rationalities which influences performance. It is contextually based and different stake- 
holders within a project understand inputs to and outputs from the project on very different incomplete and often competing ways. These different views; Type A, B and C in the opinion of the author affect how value may be perceived. Type $\mathrm{C}$ argument is more aligned to the rationale that more understanding of how megaprojects are conceived and materialised, is necessary to successful implementation.

Other characteristics of megaprojects highlighted include its enormous use of resources (physical, human, social, environmental resources etc), the inherent risks, complexities and uncertainties associated with megaprojects and the fact that megaprojects often span more than a decade. But the author is interested in how these characteristics impact on megaproject value for the stakeholders. But who are megaproject stakeholders? The next session discusses megaproject stakeholders.

\section{Stakeholders and Value}

By previously defining and reviewing megaproject, we set the context for which stakeholder value is thus discussed and how value is perceived by stakeholders. Zhai and colleagues (Zhai et al., 2009) state that the value of project management has two streams; value from project outcome and value from project management deployment. Similarly, the author argues that the internal stakeholders (owner/client) are concerned with the value from 'project management deployment' while the external stakeholders are primarily concerned with the 'value from project outcome'. The author uses the categorisation of internal and external stakeholders (Megaproject Cost Action, 2012) where internal stakeholders are the client/ customer and contractors while external stakeholders are others (including public organisations, authorities, public, Non governmental organisations (NGOs) etc.

From Table 2, the three authors have similar parties as stakeholders but Fly-

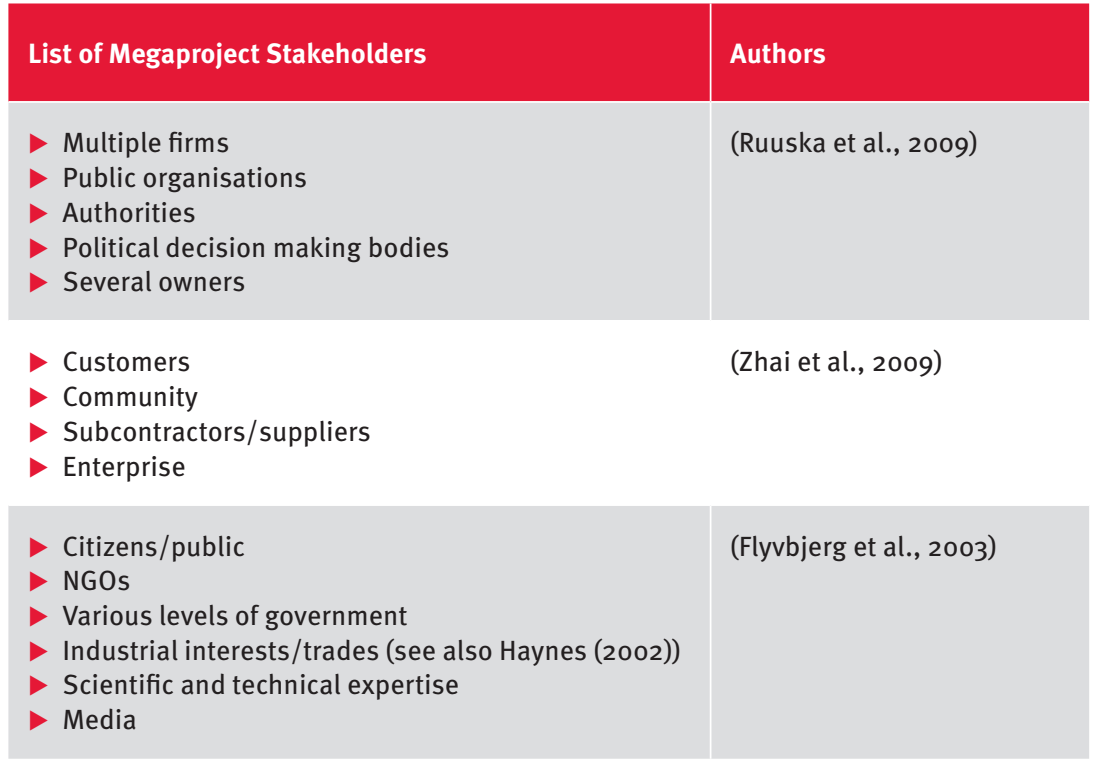

\section{Table 2 Different Authors Categorise Megaprojects Stakeholders}

Source: Author

vbjerg and colleagues include Industrial interests/trades, scientific and technical experts and the media. Ordinarily one can consider the first two parties under public but the author argues that the roles they can play especially in the knowledge economy (Harvey and Lusch, 1999) make them serious megaproject stakeholders worth mentioning. In particular, the media holds a unique position in the megaproject process (El-Gohary et al., 2006). Gohary and colleagues argue that in theory, the media can not be defined as a stakeholder because they have no actual stake in the project. However the media can have tremendous effect on the projects outcome, both positive and negative. Therefore in practice, they operate as major stakeholders. For example opponents of project searched for extensive international media attention by organising a scene at an EU meeting (Ahlemann et al., 2009).

Using the classification of stakeholders by Mitchell, Agle and Wood (Mitchell et al., 1997) within the context of Megaprojects, stakeholders can impact project success up to the extent that they have power to influence the project activities (e.g. the client, contractor etc), legitimacy of the stakeholders' relationship with the project (e.g. community the project is located) and the urgency of the stakeholders claim on the project (e.g. a fatality due to health and safety breach within the project location). With the complex relationships that exist among the Megaproject stakeholders, there is always the possibility that stakeholders can exhibit any of the attributes at any one time to influence the megaproject radically. This further supports the argument that the media is a stakeholder as it often appears to exhibit one of the attributes of power to influence.

To determine which stakeholders have the most influence and impact on the megaproject, applying the stakeholder classification of Mitchell and co authors would be very useful, but the context of the megaproject and the phase in the project lifecycle or product lifecycle is equally important as stakeholders may change or their involvement becomes more or less important with time. Just like the impact of megaprojects can be short or long term, internal and external stakeholder concerns can be short or long term. For example, some of the benefits and legacy of the 
Olympics will be experienced while the games are on but most will be experienced long after the games (London 2012, 2012).

According to Olander and Landin inadequate management of the concerns of stakeholders often leads to conflicts and controversies about the implementation of a construction project (Olander and Landin, 2005). Megaprojects can have positive or negative effects on stakeholders and these effects can either be tangible or intangible therefore the value generated by megaprojects could be negative or positive, tangible or intangible. For example, Public and stakeholder opposition have been reported as the main reason for failures of major PPP transportation projects in several instances (El-Gohary et al., 2006). Another example by Ruuska and colleagues show that the way the main contractor handled subcontracting in the Olkiluoto 3 project allowed conflicts to arise due to multiple nationalities with different cultures on site. Therefore effectively managing both internal and external stakeholders' would impact on the value generated by megaprojects.

\section{External Stakeholders and} Value from the Project Outcome The importance of involving stakeholders early on in megaproject planning and design has been discussed vigorously (Flyvbjerg et al., 2003). The main aim of involving the public in the planning and design phases of the project is to inform stakeholders and obtain their feedback regarding the most suitable design of a project, a two-way process (El-Gohary et al., 2006). El-Gohary and colleagues also state that in the construction phase, stakeholder involvement is usually a 1-way process. It usually focuses on the dissemination of construction related information to the public (road closures, construction sequence etc) and creating problem solving channels in case construction activities affect the local community in any way.
A framework highlighting eight major ways to assess how external stakeholders can influence the realisation of megaprojects was developed (ElGohary et al., 2006). The author uses this framework to discuss how engaging with external stakeholders creates megaproject value.

\section{Stakeholder Involvement Con-} cerns: These are concerns related to the involvement scope, involvement process, involvement schedule and evaluation criteria of alternatives and designs.

Stakeholders directly affected, the public and groups that are concerned by the outcome of the consultation process are either not involved or are only involved to a limited extent (Bruzelius et al., 2002). When they are involved, information is often communicated late after major decisions have been made. Attempts to include the public in the UK can be seen in practice by local councils asking for feedback on proposed plans. Another example is the governments' consultation on high speed rail in the UK (Department for Transport, 2012). This phase went wrong with the NHS IT project, where the users were not consulted during the planning and design phase (Sky News, 2011). Value can either be created or destroyed in this phase if this process is badly managed.

2. System Performance Concerns: These are related to the desired performance characteristics and attributes of infrastructure systems such as comfort, person-carrying capacity etc. These concerns in particular involve the end users and their specifications. For example, the high-speed rail link between Cologne and Frankfurt was originally designed with one stop between the two cities but after several iteration of the consultation process became five stops (Flyvbjerg et al., 2003). This went on to affect the travel time, which in turn affected the de- mand, hence the viability of the project. Understanding the performance characteristics is very important but is often compromised to satisfy the multiple stakeholders involved.

3. Environmental Concerns: These are related to noise, vibration, air pollution, climate change, water pollution, soil quality change, landscape, wildlife, fresh habitat, vegetation, visual intrusion etc.

Most NGOs and environmentalists are actively involved with environmental issues. They are usually concerned about the impact to the environment and impact on eco balance. For example, the high-speed Hannover-Berlin rail link had major changes made to the original plan to preserve the breeding area of rare bustards (Flyvbjerg et al., 2003).

4. Safety Concerns: These address both construction area safety and operation safety including safety of drivers, pedestrians, motorist, cyclist etc.

Government and its overseeing agencies and construction companies are responsible for allaying the fears of stakeholders. The government takes an active role by ensuring that the safety standards are met and the commissioned organisations ensure the safety of their workers and the general public by effectively communicating safety requirements. Furthermore, the trades will also be concerned as a matter of members' safety and the reputation of the profession.

5. Social Concerns: This relates to various welfare issues of the society including quality of life, effects on public health, accessibility of public to various facilities, impact on demographics and housing effects on the vulnerable groups, preservation of cultural heritage, national pride, community cohesion, promotion of active transportation etc.

The impact of megaprojects on social welfare affects the communities in the immediate environs. It is the primary concern of Government and 
its overseeing agents such as local councils to ensure minimum impact on the way of life on the stakeholder communities. Some NGOs will also have vested interests with regards to social welfare. For example, with the London 2012 underway, NGOs are working closely with the government and its private partners to ensure that the legacy of the Olympics is maintained post Olympics (London 2012, 2012, Legacy Trust).

6. Economic Concerns: Economic concerns include various critical issues, such as impact on land value, impact on businesses, impact on international trade, impact on tourism, impact on employment, impact on taxation, project financing, rate hikes and contractual agreements.

Businesses act according to an economic rationality-that is, one based on achieving turnover by supplying goods or services to consumers (Theurillat and Crevoisier, 2012). Infrastructure can impact on businesses positively and the value of land (Flyvbjerg et al., 2003). On the other hand, communities are concerned about job creation, investor attractiveness etc. Broadly speaking, there are two kinds of megaprojects; those that are located close to people (communities) and those located away from people. Infrastructure located close to people (London 2012, 2012) would be expected to drive the economy in the local region which is expected to drive regional and national growth. On the other hand, for infrastructure located away from people depending on its usefulness and safety requirements e.g. nuclear plants etc, it would create specialist jobs for the area but may also raise concerns for safety.

7. Political Concerns: These are the effects of project development on politics, including reelection, taxation policies, support of official plan etc.

For example, with regards to con- struction megaprojects, infrastructure plays a key role in the globalisation and knowledge economy and megaprojects are central to the new politics of distance because infrastructure is increasingly being built as megaproject (Flyvbjerg et al., 2003). They give this as a reason for the increase in the magnitude and frequency of major infrastructure projects, with support from governments (van Marrewijk, 2007) and funding bodies such as the European Union, private capital and development banks.

Megaprojects are political in nature. Flyvbjerg and colleagues suggest that politicians who are involved in producing overoptimistic forecasts of project viability in order for the projects to be approved are usually not in office when they are implemented (Flyvbjerg et al., 2003). The question then is why do politician want Megaprojects approved during their time in office, could it be that project is seen as a public good, or enjoying the goodwill from promoting green building standards (Theurillat and Crevoisier, 2012) or is it to promote political ambition? Flyvbjerg and co authors go on to say that interests groups (lobbyists) can promote projects at no cost to them and contractors and interest groups have minimal contractual penalties for overoptimistic tenders with the possibility of great financial gain if the project is approved.

8. Travel Concerns: This mainly refers to issues such as accessibility, traffic flow, traffic time and inter-region connectivity. It includes cycling concerns, parking concerns, public transit concerns, traffic concerns and urban design and street scaping concerns.

Communities and the general public are interested to know of what impact a megaproject will have on accessibility and travel time, whether during the construction phase or after completion of the project. For example there were concerns over potential traffic problems after the Terminal 5 of Heathrow was built. But in order to mitigate this, extensions were made to the Piccadilly line and the Heathrow express (Milford, 2006)

The eight concerns discussed impact on the megaprojects characteristics already highlighted. For example, economic concerns are particularly important as megaprojects are known to underperform and political concerns are especially important because megaprojects may span more than one political dispensation which can affect the project scope and financing. Therefore, external stakeholder are interested in the 'value of the project'.

\section{Internal Stakeholders and Value from the Project Management Deployment}

With regards to internal stakeholders, there are two major categories: the client/owner and the contractors. From the perspective of client/owner, there are two possibilities: they either use project management or they do not. Apart from the obvious triangle of cost, quality and time, the client or customer would be interested to know of 'what value project management is to them'. This could for instance be in the form of communication management but the extent to which they are concerned may depend on their involvement with project management. On the other hand, the contractor will be directly involved in the project management process and will equally be concerned about the value of project management to their organisation and how it contributes to their competitive advantage. For example, reputation derived from successfully completing a megaproject and the potential of new business opportunities as a result.

Hurt and Thomas using case study methodology investigate three organisations and in all three, senior management, project managers, project spon- 
sors, and customers reported benefits and satisfaction with the project management implementation as they recognise that project management competency is critical (Hurt and Thomas, 2009). Even small to medium scale organisations are concerned about their project management implementation and the value they derive (Turner et al., 2010). According to Shuping, project management has been considered a strategic issue for successful companies (Shuping, 2009). They opine that organisations have recognised that they need to have a structured project management methodology but questions have arisen such as: How can we prove that spend money in project management worth? How can we improve management level commitment to project management without the accountability of results? This implies that methodology to determine the value of project management to an organisation is very important. Project Management maturity models are an example of attempts to develop, measure and monitor value from project management deployment to organisations. But research on project management maturity models show that project management practices that are far ahead of other corporate processes can breed mistrust (Crawford, 2006) and that there are diminishing returns on higher levels of PM maturity (Kwak and Ibbs, 2002) which was also reported in research into PMO's (Hurt and Thomas, 2009). Therefore, the author argues that for organisations, gaining value from project management deployment is a balancing act which must consider the business context and environment; it is not a static process but a dynamic one.

\section{Value framework}

From the review of extant literature, broadly speaking the author has deduced that the internal stakeholders (owner/client) are concerned with the value from 'project management deployment' while the external stakehold-
Internal Stakeholders e.g.:

- Organisation

$>$ Contractors

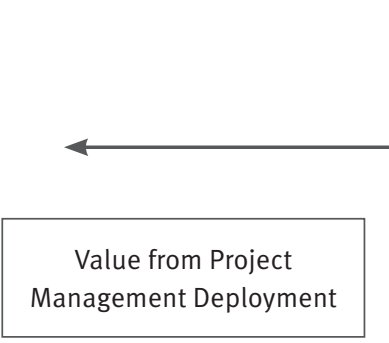

Figure 1 Value Framework

ers are primarily concerned with the 'value from project outcome'. It can be argued that this framework can be used for any project, which may be true but may not be necessary for every project. This framework is important and necessary for megaprojects because of the inherent characteristics they possess; the colossal use of resources, the impact on stakeholders especially external and most importantly the high records of poor performance etc. For researchers, the framework is recognised once the reviewer determines if the article is written with external stakeholders or internal stakeholders as the reference point. In practice, organisations can use this framework to identify what value needs to be generated for both internal and external stakeholders. For example, a subcontractor in a megaproject can use this framework to identify its internal and external stakeholders and strategise how to create value-from project management deployment and from the project outcome to satisfy them all.

\section{Conclusion}

Ideas of value in project management have changed from the single dimensional view to the multidimensional view. The value framework is based on the argument that project management value has moved from ideas of 'value management' to ideas of 'understanding how stakeholders value different things'. This value framework which describes value broadly as internal stakeholders-primarily concerned with the
External Stakeholders e.g.:

$>$ Government

- Nongovernmental Organisations (NGOs)

$\rightarrow$ Public

value from project management deployment while external stakeholdersprimarily concerned with value derived from project outcome further supports this multidimensional view.

For megaprojects, because of the duration (average of a decade) internal and external stakeholders change and become more or less important through the project and product lifecycle. Determining how stakeholders changes occur through the project life cycle phases and the impact on value creation will help organisations better deliver project value whether tangible or intangible. This process is equally important for megaprojects post completion. This will ensure that there is a greater understanding of value from the perspective of the organisations who deliver these projects to the end user who uses it.

But more research should be done to understand the relationship between cost and megaproject value-would it be better to have several smaller projects to the same value of money than one megaproject? What will be the effects in terms of value- short and long term, for all the stakeholders involved? Furthermore, research should be done on value derivation at different project phases for internal and external stakeholders. Does the relationship between the client/owner and contractors affect the value creation for external stakeholders and to what extent? 


\section{References}

AHLEMANN, F., TEUTEBERG, F. \& VOGELSANG, K. 2009. Project management standards Diffusion and application in Germany and Switzerland. International Journal of Project Management, 27, 292-303.

BRUZELIUS, N., FLYVBJERG, B. \& ROTHENGATTER, W. 2002. Big decisions, big risks. Improving accountability in mega projects. Transport Policy, 9, 143-154.

CRAWFORD, J. K. 2006. THE PROJECT MANAGEMENT MATURITY MODEL. Information Systems Management, 23, 5058.

DEPARTMENT FOR TRANSPORT. 2012. Available: http://highspeedrail.dft.gov.uk/ [Accessed 31/07/2012 2012].

EL-GOHARY, N. M., OSMAN, H. \& EL-DIRABY, T. E. 2006. Stakeholder Management for Pubilc Private Partnerships. International Journal of Project Management, 24.

EWEJE, J., TURNER, R. \& MÜLLER, R. 2012. Maximizing strategic value from megaprojects: The influence of informationfeed on decision-making by the project manager. International Journal of Project Management.

FLYVBJERG, B., BRUZELIUS, N. \& ROTHENGATTER, W. 2003. Megaprojects and Risks: An Anatomy of Ambition, Cambridge.

FORICEL, S. \& MILLER, R. 2001. Strategizing for Anticipated Risks and Turbulence in the Implementation of Construction Projects. International Journal of Project Management, 19.

FRICK, K. T. The cost of technological sublime: daring ingenuity and the new San Francisco Oakland Bay Bridge.

HARVEY, M. G. \& LUSCH, R. F. 1999. Balancing the intellectual capital books: intangible liabilities. European Management Journal, 17, 85-92.

HAYNES, W. 2002. TRANSPORTATION AT THE MILLENNIUM: In Search of a Megaproject Lens. Review of Policy Research, 19, 62-64.

HOBBS, B., AUBRY, M. \& THUILLIER, D. 2008. The project management office as an organisational innovation. International Journal of Project Management, 26, 547-555.

HURT, M. \& THOMAS, J. L. 2009. Building value through Sustainable project Management Offices. Project Management Journal, 40, 55-72.
JIA, G., YANG, F., WANG, G., HONG, B. \& YOU,

R. 2011. A study of mega project from a perspective of social conflict theory. International Journal of Project Management, 29, 817-827.

KEEGAN, A. 2004. Transformational leadership in a project-based environment: a comparative study of the leadership styles of project managers and line managers* 1 . International Journal of Project Management, 22, 609-617.

KWAK, Y. H. \& IBBS, C. W. 2002. Project Management Process Maturity (PM) [sup 2] Model. Journal of Management in Engineering, 18, 150.

LEGACY TRUST, U. Available: http://www. legacytrustuk.org/ [Accessed 31/07/2012 2012].

LONDON 2012 2012. London 2012 Sustainability report.

MEGAPROJECT COST ACTION. 2012. 1/08/2012].

MILFORD, A. 2006. Leeds. Available: http:// www.getsurrey.co.uk/news/s/53244_ terminal_5_will_bring_congestion [Accessed 31/07/12 2012].

MITCHELL, K. R., AGLE, R. B. \& WOOD, J. D. 1997. Toward a Theory of Stakeholder Identification and Salience: Defining the Principle of Who and What Really counts. Academy of Management Review, 22.

OLANDER, S. \& LANDIN, A. 2005. Evaluation of Stakeholder Influence in the Implementation of Construction Projects. International Journal of Project Management, 23.

PATAH, L. A. \& DE CARVALHO, M. M. Measuring the value of project management. PICMET '07. 2007 Portland International Conference on Management of Engineering and Technology, 5-9 Aug. 2007, 2007 Piscataway, NJ, USA. IEEE, 2038-42.

RUUSKA, I., ARTTO, K., AALTONEN, K. \& LEHTONEN, P. 2009. Dimensions of distance in a project network: Exploring Olkiluoto 3 nuclear power plant project. International Journal of Project Management, 27, 142-153.

SANDERSON, J. 2012. Risk, uncertainty and governance in megaprojects: A critical discussion of alternative explanations. International Journal of Project Management, 30, $432-443$

SHUPING, Y. 2009. An Assessment

Methodology for Economic Benefit of Project Management. 176-179.
SKY NEWS. 2011. Calls to Pull Plug On Costly NHS E-Records [Online]. Available: http://news. sky.com/home/uk-news/article/16042614 [Accessed 4/08/11 2011].

STODDART-STONES, R. 1988. Development of project management systems for major projects. International Journal of Project Management, 6, 34-38.

STURUP, S. 2009. Megaprojects and Governability. World Academy of Science, Engineering and Technology, 54.

SYKES, A. 1998. MEGAPROJECTS: Grand schemes need Oversight, Ample Funding. Forum for Applied Research and Public Policy, 13, 6-47.

THEURILLAT, T. \& CREVOISIER, O. 2012. The Sustainability of a Financialized Urban Megaproject: The Case of Sihlcity in Zurich. International Journal of Urban and Regional Research, no-no.

THOMAS, J. L. \& MULLALY, M. 2009.

Explorations of value: Perspectives of the value of project management. Project Management Journal, 40, 2-3.

TURNER, R., LEDWITH, A. \& KELLY, J. 2010. Project management in small to mediumsized enterprises: Matching processes to the nature of the firm. International Journal of Project Management, 28, 744-755.

VAN MARREWIJK, A. 2007. Managing project culture: The case of Environ Megaproject. International Journal of Project Management, 25, 290-299.

VAN MARREWIJK, A., CLEGG, S. R., PITSIS, T. S. \& VEENSWIJK, M. 2008. Managing public-private megaprojects: Paradoxes, complexity, and project design. International Journal of Project Management, 26, 591-60o.

WELZL, G. A. 2011. Values with a MeaningTowards Reporting of the 21st century. 18th International XBRL Conference.

WINTER, M., SMITH, C., MORRIS, P. \& CICMIL, S. 2006. Directions for future research in project management: The main findings of a UK government-funded research network. International Journal of Project Management, 24, 638-649.

ZHAI, L., XIN, Y. \& CHENG, C. 2009. Understanding the value of project management from a stakeholder's perspective: Case study of mega-project management. Project Management Journal, 40, 99-109. 